\title{
Liquisolid systems and aspects influencing their research and development
}

BARBORA VRANÍKOVÁ

JAN GAJDZIOK

Department of Pharmaceutics, Faculty of Pharmacy, University of Veterinary and Pharmaceutical Sciences, Brno 61242 Czech Republic

\begin{abstract}
Many modern drugs are poorly water soluble substances, which causes difficulties in the development of solid dosage forms with sufficient bioavailability. Preparation of liquisolid systems (LSS) is a novel technique for improving solubility, dissolution and bioavailability of such drugs. The basic principle of LSS preparation is conversion of the drug in liquid state into a free-flowing, compressible, dry powder through its absorption into suitable excipients - porous carriers (aluminometasilicates, microcrystalline cellulose), subsequently coated with material having high absorption capacity (silicon dioxide commonly known as colloidal silica). LSS exhibit advantages such as lower production costs compared to soft capsules, simple processing and enhanced drug release. The main benefit is higher bioavailability of the liquid drug, caused by a large surface area available for absorption. The article tries to clarify specific aspects connected with the formulation of LSS: properties of excipients (surface area, absorption capacity), variables related to the processing (solubility, liquid load factor) and dosage form evaluation.
\end{abstract}

Keywords: bioavailability improvement, carrier material, enhanced release, liquid drug, liquisolid technology

The Biopharmaceutical Classification System (BCS) is a scientific approach for classifying active pharmaceutical ingredients (APIs) based on their aqueous solubility and gastrointestinal permeability $(1,2)$. Many of potentially new drugs exhibit poor water solubility and belong to BCS class II (high permeability) or BCS class IV (low permeability). For poorly soluble and highly permeable drugs (BCS class II), the solubility and dissolution behaviour of the drug are the most important parameters for bioavailability (3).

Due to their low bioavailability, poorly water-soluble drugs cause many difficulties in the development of pharmaceutical dosage forms for oral delivery $(4,5)$. Different

\footnotetext{
* Correspondence; e-mail: vranikovab@vfu.cz
} 
techniques have been published in the scientific literature to enhance the dissolution profile and also the absorption efficiency and bioavailability of water-insoluble and/or liquid lipophilic drugs. Reduction of the particle size via micronisation or nanonisation leading to increased surface area (6); use of surfactants (7); lyophilisation (8); use of co-solvents (9); self-emulsification and self-microemulsification (10, 11); inclusion of APIs into cyclodextrins (12); use of pro-drugs and drug derivatisation (13); formation of solid solutions or amorphous solids (14); microencapsulation (15) and inclusion of drug solutions or liquid drugs into soft gelatine capsules or sealed hard shell capsules (16) are some of the methods used to enhance dissolution characteristics of water-insoluble or poorly soluble drugs (Fig. 1). The most promising and innovative technique for promoting dissolution and in vivo bioavailability of poorly soluble drugs is the formulation of liquisolid systems (LSS) $(5,17,18)$.

From the historical point of view, liquisolid systems evolved from "powdered solutions «, which are based on preparation of a true solution of the drug in a high-boiling point, water-miscible solvent, which was incorporated into the structure of an inert carrier with a large surface (colloidal silica) (19). However, such preparations have been investigated for their dissolution profiles in a powder-dispersion form because they were not suitable for compression into tablets. To increase the compressibility of the systems, compression enhancers such as microcrystalline cellulose were added to powder solution formulations. However, properties of the products were never adapted to industrial requirements (20).

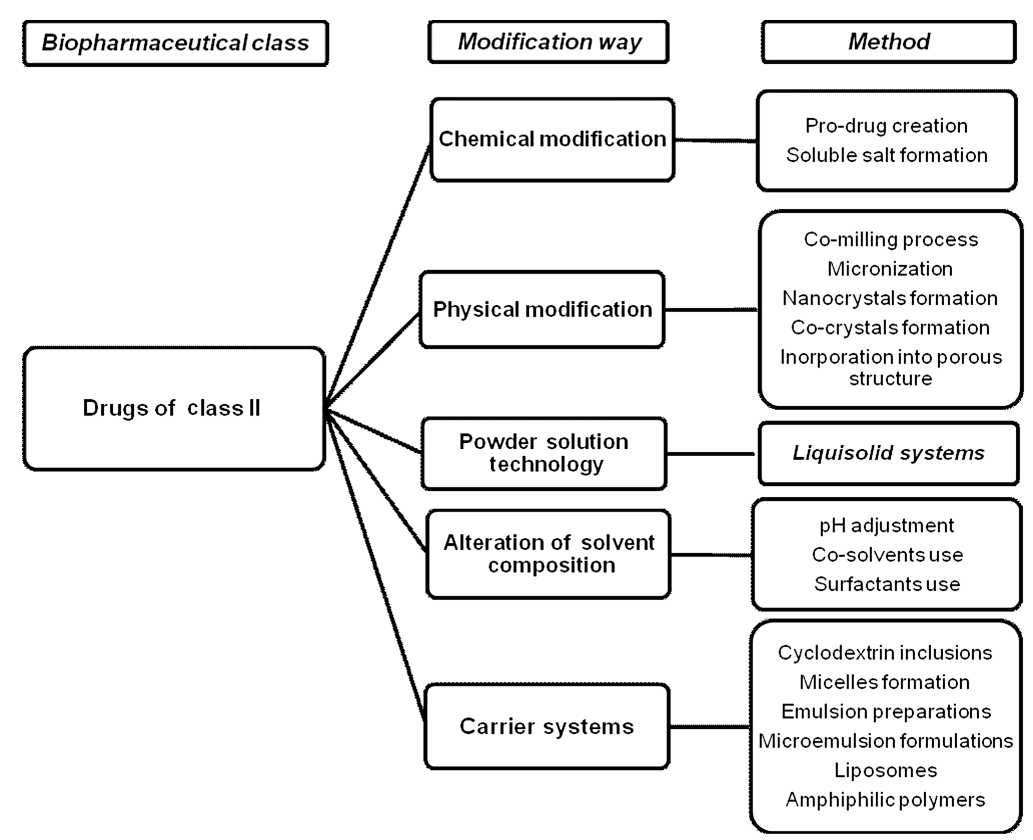

Fig. 1. Various techniques that can be used to enhance drug solubility (19). 
Technological improvement of preparing powdered solutions were the liquisolid systems, which essentially refer to formulations formed by conversion of liquid drugs or drugs in liquid state (solutions, suspensions or emulsions) into dry, non-adherent, free-flowing and compressible powder mixtures by blending a liquid dispersion with specific carriers and coating materials (19).

The common basis of liquisolid systems are non-volatile solvents (or drugs alone) used to prepare a drug solution, suspension or emulsion, which do not evaporate during the preparation process and thus the drug is carried within the liquid system, which in turn is dispersed throughout the final solid product (20). Unlike solid self-emulsifying systems, hydrophilic solvents are used to obtain the drug in liquid solution during the preparation of liquisolid systems. Moreover, the drug solution does not form an emulsion (microemulsion) after agitation in the gastrointestinal tract.

\section{ADVANTAGES, LIMITATIONS AND APPLICATION OF LIQUISOLID SYSTEMS}

Liquisolid systems have many advantages (17, 19, 21-24):

- Increased bioavailability and enhanced in vitro and in vivo drug release of an orally administered water-insoluble drug, achieved when the drug is in the liquid form.

- A number of water-insoluble solid and liquid drugs can be formulated into liquisolid systems.

- LSS can be used for controlled drug delivery.

- Liquisolid systems minimize pH influence on the dissolution rate of poorly soluble drugs.

- The final processing of liquisolid systems could be similar to conventional solid dosage forms (tablets, capsules).

- Low production costs.

Limitations of LSS include the requirement of high solubility of the drug in non-volatile liquid vehicles if drug solutions are used (17). The main limitation of LSS is the problematic formulation of a high dose of poorly water soluble drugs (e.g., carbamazepine, flutamide). These drugs require a large amount of liquid vehicle and also carrier and coating material to prepare dry powder with suitable flowability and compressibility. This could increase the mass of each tablet over the limit for easy application $(21,25)$. Nevertheless, Javadzadeh et al. (26) have proven that it is possible to load a large amount of drug into a liquisolid system using additives (such as polyvinylpyrrolidone, hydroxypropyl methylcellulose and polyethylene glycol 35 000), which can be added to the drug in liquid state to reduce the amount of carrier and coating material. Singh et al. (27) have shown that higher viscosity of the additives leads to smaller amounts of carrier and coating material needed to produce flowable powder. The use of modern carriers and coating materials with a large specific surface area and high absorption capacity (e.g., Neusilin $\left.{ }^{\circledR}\right)$ is another way of incorporation of higher doses of water insoluble drugs into liquisolid systems (28). 
Application of liquisolid systems $(3,17,22)$ :

- Dosage forms with enhanced release rates and improved bioavailability.

- Sustained release of water-soluble drugs (propranolol hydrochloride) can be attained.

- Liquisolid technique can be successfully used in formulation of orodispersible tablets.

Several liquisolid formulations, which were studied in vivo, have already been described in literature. For example, El-Houssieny et al. (29) investigated the effect of liquisolid compacts containing repaglinide on glucose tolerance in rabbits. They proved that the bioavailability of repaglinide was improved significantly when it was administered orally in the form of liquisolid compacts compared to commercially available tablets.

Khaled et al. (30) evaluated in vivo the behaviour of liquisolid tablets with hydrochlorothiazide in beagle dogs. Liquisolid tablets showed higher values of $A U C_{\mathrm{t}}, A U C_{\propto}$, $C_{\max }$ and $F$ parameters than commercial hydrochlorothiazide tablets. The mean values of absolute bioavailability of hydrochlorothiazide from liquisolid tablets were increased by $\sim 15 \%$ in comparison with commercially available tablets.

During in vivo evaluation of carbamazepine liquisolid tablets, it was observed by Chen et al. (31) that absolute bioavailability of carbamazepine was increased by $82 \%$ in comparison with commercially available tablets.

Evaluation of liquisolid tablets containing famotidine showed a higher dissolution rate than the conventional, directly compressed tablets. Liquisolid formulation released $78 \%$ of famotidine during the first $10 \mathrm{~min}$, which is $39 \%$ more than the release from directly compressed tablets (32).

\section{FORMULATION OF LIQUISOLID SYSTEMS}

Preparation of liquisolid systems is based on the principles of conversion of the drug in the liquid state into a free flowing, readily compressible and apparently dry powder by simple physical blending with selected excipients, excipients - carriers and coating materials. Liquid drug could be also sprayed into the carrier material in fluid-bed equipment for homogenous distribution of the active substance. Liquid drug is incorporated into the porous structure of a carrier material due to adsorption and absorption $(17,33,34)$.

\section{Excipients for liquisolid systems}

Non-volatile solvents. - Various non-volatile, high-boiling point, preferably water miscible and not highly viscous solvents are used for the formulation of liquisolid systems. It was proven in several studies that the solvent had a significant effect on drug release from liquisolid systems $(35,36)$. For enhanced drug release from liquisolid preparations, a liquid vehicle in which the active ingredient is most soluble is usually selected. In the case of preparing liquisolid systems with modified release, solvents with a low capability to solubilize the drug are used. 
Propylene glycol (PG) is commonly used in the pharmaceutical industry as a stabilizer for vitamins, humectant and co-solvent in ointments for medicinal applications (37). The main function of propylene glycol is to solubilize and provide homogeneous dispergation of the active ingredient in the formulation (38).

In their study, Gubbi and Jarag (39) found out that liquisolid compacts with bromhexine hydrochloride prepared using propylene glycol showed a higher dissolution rate than bromhexine hydrochloride with PEG 400. The slower release of bromhexine hydrochloride from PEG 400 liquisolid compacts can be attributed to lower solubility of bromhexine hydrochloride in polyethylene glycol 400.

Liquid polyethylene glycols (PEG 200-600) are widely used as solvents and solubilizing agents for active substances and excipients in liquid and semi-solid preparations (40). Aqueous polyethylene glycol mixtures can also be used as suspending agents or as thickeners. When used in conjunction with emulsifiers, polyethylene glycols can act as emulsion stabilizers (41).

Mahajan et al. (34) investigated the effect of the type of non-volatile solvent on the dissolution profile of glipizide from liquisolid tablets. Propylene glycol, PEG 200 and PEG 400 were used to prepare liquisolid formulations in that study. It was observed that all three liquid vehicles were able to increase the dissolution rate of glipizide from liquisolid tablets in comparison with their commercial counterparts. Liquisolid tablets containing PEG 400 as liquid vehicle showed higher dissolution rates compared to liquisolid tablets containing PG and PEG 200 as liquid vehicles (34).

Polyoxyethylene sorbitan fatty acid esters (Polysorbate, Tween) are widely used in pharmaceutical and cosmetic industry as emulsifiers, dispersants or stabilizers because of their effectiveness at low concentrations and relatively low toxicity (41-43). In addition, polysorbates are compatible with the majority of active ingredients (44). The most commonly used polysorbate in liquisolid systems is Polysorbate 80.

Polysorbate 80 was successfully used to dissolve the drug in several liquisolid systems containing carbamazepine $(26,45)$, indomethacin $(46,47)$, piroxicam $(48)$, propranolol hydrochloride (35), etc.

Other solvents that can be used in formulation of liquisolid systems include glycerol, $N, N$-dimethylacetamide, Synperonic ${ }^{\circledR} \mathrm{PE} / \mathrm{L} 81$ (polyoxyethylene-polyoxypropylene block copolymer), Caprol ${ }^{\circledR}$ PGE-860 ((9Z)-9-octadecenoate), Labrasol ${ }^{\circledR}$ (caprylocaproyl macrogol-8 glycerides), Transcutol ${ }^{\circledR} \mathrm{HP}$ (highly purified diethylene glycol monoethyl ether), Solutol ${ }^{\circledR}$ HS-15 (macrogol 15 hydroxystearate) and Cremophor ${ }^{\circledR}$ EL (macrogol glycerol ricinoleate), which was used in studies (49) partially due to its known inhibition effect on P-glycoprotein. This P-glycoprotein decreases the drug intestinal absorption by efflux transportation and hence reduces its plasma concentration $(18,49-52)$. Also Kollicoat ${ }^{\circledR}$ SR 30D (polyvinyl acetate stabilized with polyvinylpyrrolidone and sodium lauryl sulphate) can be used as a liquid vehicle in liquisolid systems for controlled drug release $(52,53)$.

Carrier materials. - In the LSS preparation technique, carrier materials play the main role in obtaining the dry form of powder from the drug in liquid state. Each carrier has its unique properties, but each should be a porous material possessing sufficient absorption capacity for liquids (21). It was observed that the specific surface area (SSA) (Table I) of the carrier is an important factor in the formulation of liquisolid systems (23). Car- 
B. Vraníková and J. Gajdziok: Liquisolid systems and aspects influencing their research and development, Acta Pharm. 63 (2013) 447-465.

Table I. Classification of carrier material into four categories and their SSA (28, 54-56)

\begin{tabular}{llc}
\hline Carrier category & Carrier & $\mathrm{SSA}\left[\mathrm{m}^{2} / \mathrm{g}\right]$ \\
\hline Cellulose and cellulose & microcrystalline cellulose & $\sim 1.18$ \\
derivatives & hydroxypropyl methylcellulose ${ }^{\mathrm{a}}$ & - \\
\hline \multirow{2}{*}{ Saccharides } & lactose & $\sim 0.35$ \\
& sorbitol & $\sim 0.37$ \\
\hline \multirow{2}{*}{ Silicates } & magnesium aluminometasilicate & $110-300$ \\
& kaolin & $\sim 24$ \\
& diosmectite & - \\
\hline & ordered mesoporous silicates & up to 1500 \\
\hline Others & anhydrous dibasic calcium phosphate & 30 \\
& polymethacrylates & - \\
& starch & $\sim 0.60$ \\
\hline
\end{tabular}

a Carrier material for LSS with controlled drug delivery

rier selection depends on its liquid binding capacity, flowability of powders and compressibility (19). Based on their chemical structure, carriers can be classified into four categories (Table I).

Microcrystalline cellulose (MCC, Avicel ${ }^{\circledR}$, Ceolus $^{\circledR}$, $\operatorname{Vivapur}^{\circledR}$, Emcocel $^{\circledR}$ ) is the most commonly used carrier in liquisolid formulations based on its long-term application in the pharmaceutical industry, its stability and availability. It was used to formulate LSS containing aceclofenac (57), diazepam (58), furosemide (50), etc. (Table II).

It was observed in previous studies that carriers other than MCC (such as lactose, starch or sorbitol) were required in larger amounts for conversion of liquid preparations to the dry, non-adherent, free-flowing powder form. This was attributed to the larger specific surface area of MCC (Table I) (23).

Magnesium aluminometasilicates $\left(\right.$ Neusilin $^{\circledR}$, Pharmsorb $^{\circledR}$, Veegum ${ }^{\circledR}$ ) are available in various grades (e.g., 11 grades of Neusilin ${ }^{\circledR}$ ) and two different $\mathrm{pH}$ options (alkaline $\mathrm{pH}$ 8.5-10.0 and neutral $\mathrm{pH}$ 6.5-8.0), which make them versatile excipients for a wide variety of applications. The most prominent magnesium aluminometasilicate Neusilin ${ }^{\circledR}$ can be used in direct compression and also in wet granulation (59). Neusilin ${ }^{\circledR}$ US2 is prepared by spray drying and thus provides an extremely large specific surface area, high porosity and good flow and tableting properties. The high porosity and large SSA of Neusilin ${ }^{\circledR}$ cause its high oil and water adsorption capacity (Fig. 2) $(60,61)$.

In liquisolid system preparation, Neusilin ${ }^{\circledR}$ can be used as a carrier or also as a coating material (see below). For example, Neusilin ${ }^{\circledR} \mathrm{S} 1$ was used as a material absorbing excess liquid in the LSS tablets of cyclosporine A. Compared to conventional cyclosporine tablets, the drug release from the liquisolid tablets exhibits a significant improvement (63).

Anhydrous dibasic calcium phosphate (Fujicalin ${ }^{\circledR}$, Emcompress ${ }^{\circledR}$ Anhydrous). Fujicalin ${ }^{\circledR}$ is a free-flowing spherically agglomerated anhydrous dibasic calcium phosphate for 
B. Vraníková and J. Gajdziok: Liquisolid systems and aspects influencing their research and development, Acta Pharm. 63 (2013) $447-465$.

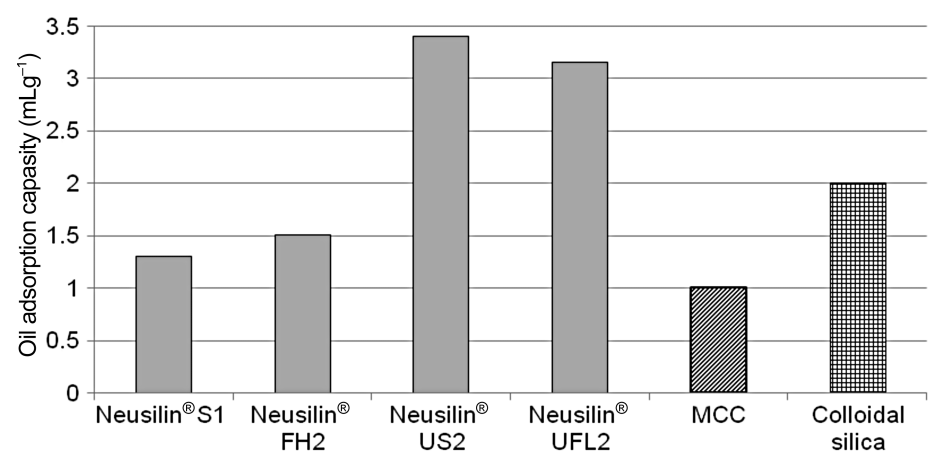

Fig. 2. Oil adsorption capacity of some grades of Neusilin ${ }^{\circledR}$ in comparison with MCC and colloidal silica (62).

direct compression (64). It was observed that Fujicalin ${ }^{\circledR}$ had higher liquid adsorption capacity in comparison with directly compressible dicalcium phosphate dihydrate $(65,66)$.

Therefore, Fujicalin ${ }^{\circledR}$ can be used as a carrier material in liquisolid systems, as proved by Hentzschel et al. (28). In their study, Fujicalin ${ }^{\circledR}$ was used to prepare a liquisolid system containing Tocopherol acetate as a model drug (28).

Based on their large SSA, several other excipients can be used as potential carriers in a liquisolid formulation, such as kaolin $\left(\operatorname{Lion}^{\circledR}, \operatorname{Sim}^{\circledR} 90\right)$, diosmectite and magnesium carbonate.

Ordered mesoporous silicates (OMS) (SBA-15, MCM-41, TUD-1) could also have a high potential in this field. They were originally developed for controlled drug release formulations (67-69) and their capability to enhance the release of poorly soluble drugs was discovered later $(56,70,71)$. In recent studies, it was observed $(72,73)$ that drugs lose crystallinity when deposited on the surface of mesoporous silicates, which enhances their dissolution rate. In comparison with non-porous materials, deposited molecules are not only absorbed onto the mesoporous silica surface but are also confined to pores (56).

Because of their high specific surface area (up to $1500 \mathrm{~m}^{2} \mathrm{~g}^{-1}$ ), OMS could be used as a carrier material in liquisolid systems. Chen et al. (31) successfully used an ordered mesoporous carrier as coating material to formulate liquisolid systems containing carbamazepine as a model drug, PEG 400 as a non-volatile solvent and MCC or starch 1500 as carrier materials. The significant improvement of drug loading and dissolution rate demonstrated that those formulations could provide enhanced dissolution of poorly water-soluble drugs $(31,74)$.

Coating materials. - Coating material should be a material possessing fine $(0.01-5 \mu \mathrm{m}$ in diameter) and highly absorptive particles, which contribute to covering the wet carrier particles and displaying a dry powder by adsorbing excess liquid to ensure good flowability of the created blend $(20,21)$. In liquisolid system formulations, this role is played by materials with a large specific surface area and absorption capacity, which cannot be used as carriers due to their poor flowing or compressing properties.

Nowadays, the most commonly used coating material in liquisolid formulations is colloidal silicon dioxide $\left(\right.$ Aerosil $\left.{ }^{\circledR}, \mathrm{Cab}-\mathrm{O}-\mathrm{Sil}{ }^{\circledR} \mathrm{M} 5\right)$. It was successfully used with ator- 
vastatin (75), naproxen (18), famotidine (32), rofecoxib (76), etc. (Table II). Amorphous silica gel $\left(\right.$ Syloid ${ }^{\circledR}$, Sylysia $\left.{ }^{\circledR}\right)$, granulated silicon dioxide (Aeroper $\left.{ }^{\circledR}\right)$, silica aerogel, magnesium alumino metasilicates (Neusilin ${ }^{\circledR}$ ), calcium silicate (Florite ${ }^{\circledR}$ ) and ordered mesoporous silicates can be also used to prepare liquisolid system with suitable flowability and compressibility $(28,29,31,77-79)$.

\section{Pre-formulation studies}

Pre-formulation studies are necessary to achieve a powder mixture with acceptable powder flow and liquisolid formulations that satisfy all requirements generally imposed on tablets, capsules or granules. These studies are closely related to selection of the best non-volatile solvent to solubilize drugs and to calculate the appropriate amount of powder excipients - carrier and coating material (76).

Solubility studies are carried out by preparing a saturated solution of the drug by adding an excess of drug into non-volatile solvents and let it stay to achieve the equilibrium state (e.g., by shaking, stirring). After this step, the amount of drug dissolved in a specific solvent is evaluated analytically $(20,22)$. Solvents with greater ability to solubilize the drug are selected for the formulation of liquisolid systems for enhanced release (23).

Determination of the angle of slide $(\theta)$ is used to evaluate the flow property of powder excipients (18). Spireas et al. (80) claimed that the angle of slide is the preferred method to determine the flowability of powders with particles smaller than $150 \mu \mathrm{m}$. The required amount of carrier is weighed and placed on one end of a metal plate with a polished surface. This end is gradually raised until the plate makes an angle with the horizontal surface at which powder is about to slide. This angle is known as the angle of slide. The angle of slide of $33^{\circ}$ is regarded as optimal flow behaviour for the subsequent processing of liquisolid system admixtures (compressing into tablets, filling into capsules) $(22,23)$.

Determination of the flowable liquid retention potential (Ф-value). - The term flowable liquid retention potential of a powder material describes its ability to retain a specific amount of liquid while maintaining good flow properties. The $\Phi$-value $\left(\Phi_{\mathrm{CA}}-\Phi\right.$-value of carrier, $\Phi_{\mathrm{CO}}-\Phi$-value of coating material) is defined as the maximum mass of a liquid $\left(m_{\max }\right)$ that can be retained per unit mass of the powder material $(Q-$ mass of carrier, $q-$ mass of coating material) in order to produce an acceptably flowing liquid/powder mixture (Eq. 1) (21). The liquid retention potential is mainly dependent on the absorption process (81).

$$
\Phi_{\mathrm{CA}}=\frac{m_{\max }}{Q} \text { or } \Phi_{\mathrm{CO}}=\frac{m_{\max }}{q}
$$

Powder excipients are mixed with varying amounts of a non-volatile solvent and the angle of slide of these liquid-powder admixtures is determined. The liquid/solid mass ratio $(\mathrm{m} / \mathrm{m})$ of admixtures with the angle of slide corresponding to $33^{\circ}$ is taken as the $\Phi$-value of the excipient $(20,23,82,83)$.

Calculation of the liquid load factor $\left(\mathrm{L}_{f}\right) .-L_{\mathrm{f}}$ is defined as the ratio of the mass of drug in the liquid state $(m)$ to the mass of carrier material $(Q)$. It is determined by dissolving 
or dispersing the drug in different concentrations in a non-volatile solvent (84). Such a drug in the liquid state is added to the carrier material and blended. Using Eq. 2, drug loading factors are determined and used to calculate the amounts of carrier and coating materials in each formulation (21).

$$
L_{\mathrm{f}}=\frac{m}{Q}
$$

The powder excipients ratios $(R)$ and liquid load factors $\left(L_{\mathrm{f}}\right)$ of the formulations are related as follows $(17,19,20,22)$ :

$$
L_{\mathrm{f}}=\Phi_{\mathrm{CA}}+\frac{\Phi_{\mathrm{CO}}}{R}
$$

Evaluation of liquisolid tablets containing rofecoxib showed that the liquid load factor was inversely proportional to the hardness of the tablets, i.e., when $L_{\mathrm{f}}$ increased, the hardness of the tablets decreased. This can be explained by increasing $L_{\mathrm{f}}$ of the formula, connected with higher amount of poorly compressible coating material used during manufacture, which led to lower hardness of tablets (76). The effect of the liquid load factor on tablet hardness was also proved by evaluating liquisolid tablets containing griseofulvin as a model drug. The formulation with a lower liquid load factor showed higher hardness, which may be caused by the high concentration of Avicel ${ }^{\circledR} \mathrm{PH} 102$ (carrier) leading to plastic deformation of the powder admixture and formation of more hydrogen bonds between its molecules (53).

Liquisolid compressibility test (LSC) is used to the compressible liquid retention potential ( $\psi$-value) and to characterize the compaction behaviour of powder excipients (85). The $\psi$-value is the maximum mass of the liquid that can be retained per unit mass of the powder material to produce an acceptably compressible liquisolid admixture. In fact, this is the mass of the liquid that can afford tablets of satisfactory mechanical strength without presenting any »liquid squeezing out« phenomena during compression (23).

Calculation of the required amount of carrier and coating material. - To calculate the required mass of excipients, Eq. 3 is used first, where $\Phi_{\mathrm{CA}}$ and $\Phi_{\mathrm{CO}}$ are constants; therefore, according to the ratio of the carrier/coating materials $(R)(E q .4), L_{\mathrm{f}}$ could be calculated from the linear relationship of $L_{\mathrm{f}}$ versus $1 / R$. Next, depending on the used liquid vehicle concentration, different masses of the liquid drug $(m)$ should be used. Then, appropriate quantities of carrier $(Q)$ and coating $(q)$ powder materials required to transform a given amount of drug in the liquid state $(m)$ into an acceptably flowing and compressible liquisolid system could be calculated from Eqs. 2 and 4 (20).

$$
R=\frac{Q}{q}
$$

Powder flow (flow property) is important in the formulation and industrial production of solid dosage forms in order to get a uniform dose as well as reproducible filling of a tablet press or capsules. The angle of repose, compressibility index or Hausner ratio, flow rate through the orifice, shear cell and the related tapped and bulk density have to 
be executed according to the official pharmacopeia and are the main parameters of powder flow (84).

Pre-compression studies of liquisolid systems containing irbesartan showed that there was a relationship between the powder excipient ratios $(R)$ and the angle of repose of the liquisolid powder in the formulation having the same $L_{\mathrm{f}}$. The powder excipients ratio is directly proportional to the angle of repose of liquisolid powders, i.e., when the excipient ratio increased, the angle of repose increased too, because of poorer flowing properties of powdered blends caused by a lower content of coating material (86).

Differential scanning calorimetry (DSC) is performed in order to assess the thermal behaviours (melting point, glass transition temperature, change of crystalline structure) of the drug, excipients used in the formulation, as well as the liquisolid system prepared (20). Samples (pure drug, excipients used in the liquisolid system and liquisolid formulation) are sealed in aluminium pans and evaluated at a constant heating rate in the scanning temperature range according to the drug used (87).

DSC is also used to determine any possible interaction between the drug and excipients (or between excipients), detectable by shifting of the characteristic peak, used in the formulation. It is very important to establish the existence of any incompatibilities during the pre-compression stage to ensure the success of subsequent stability studies. The drug has a characteristic peak and the absence of this peak in the DSC thermogram indicates that the drug is in the form of solution in the liquisolid formulation and hence it is molecularly dispersed within the system $(21,22,84)$. DSC is carried out during pre-compression studies of LSS in order to ensure suitability of the selected excipients (88).

In some cases, also X-ray diffraction (XRD) studies and scanning electron microscopy (SEM) are recommended during the pre-compression studies of LSS to control the crystallinity of the drug. Disappearance of characteristic peaks or crystals of the drug generally indicates that the drug is converted into the amorphous form or is solubilized in the liquisolid formulation $(22,84)$.

\section{Preparation of liquisolid systems}

The drug is dissolved or dispersed in the required amount of a non-volatile solvent and the resulting blend is incorporated into calculated amounts of carrier and coating materials. Mixing process is carried out in three steps. During the first step, the system is blended at an approximate mixing rate in order to homogenously distribute the drug in the liquid state throughout the powder. In the second step, the liquid/powder admixture is evenly spread as a uniform layer and left standing to allow drug dispersion to be absorbed in the interior of powder particles. In the third step, the powder is blended with common excipients needed to prepare the final dosage form (tablets, capsules) (20, $22,23)$. For a homogeneous distribution of API, the drug could be applied on the particles of the carrier also by spraying in a fluid-bed equipment.

\section{Evaluation of liquisolid systems}

Liquisolid systems are evaluated in the same way as conventional tablets, granules and capsules by carrying out tests for mass variation, uniformity of dosage units, uniformity of content, hardness, friability, disintegration and dissolution, all of which are de- 
B. Vraníková and J. Gajdziok: Liquisolid systems and aspects influencing their research and development, Acta Pharm. 63 (2013) $447-465$.

scribed in official pharmacopoeias. Measured values should fall within the official limits prescribed by pharmacopoeias (89).

Contact angle measurement. - The specific method used for evaluation of physicochemical properties of LSS is measuring of the contact angle. A drop of a liquid, preferably not dissolving or poorly dissolving the sample is placed on the surface of the tablet (20). The naturally formed angle between a liquid and a solid is defined as contact angle (89). This measurement is performed to evaluate the wettability of prepared liquisolid tablets with dissolution media.

\section{LIQUISOLID SYSTEMS FOR ENHANCED DRUG RELEASE}

Many drugs of BCS class II (low solubility, high permeability), possibly of class IV (low solubility, low permeability) have been formulated as liquisolid systems to ensure enhanced drug release. To formulate these drug delivery systems, different liquid vehicles, carriers and coating materials were used, as shown in Table II.

\section{Mechanism of enhanced drug release from liquisolid systems}

Several possibilities of enhanced drug release have been described in the literature $(90,91)$. The main suggested mechanisms include: an increased surface area of the drug available for release, increased aqueous solubility of the drug and/or improved wettability of drug particles $(17,79,92)$. In addition to these mechanisms, the drug in LSS is presented in dissolved state, which allows elimination of the most limiting step during drug absorption in the gastrointestinal tract.

Increased drug surface area. - While the drug within the liquisolid system is completely dissolved in the liquid vehicle, it is still located on the whole surface of carrier material in the solubilized, molecularly dispersed state. Therefore, the surface area of the drug available for release is much larger than that of drug particles within directly compressed tablets $(17,32,92)$.

Improved wetting properties. - Wettability of the compacts by dissolution media is one of the proposed mechanisms for explaining the enhanced dissolution rate from liquisolid systems. The non-volatile solvent present in the liquisolid system facilitates wetting of drug particles by decreasing the interfacial tension between dissolution medium and tablet surface (21). Improved wettability of these systems has been demonstrated by measurements of contact angles and water rising times $(21,92)$.

Yadav V. B. and Yadav A. V. (47) claimed that liquisolid granules containing indomethacin showed significantly shorter rising time of water in comparison with raw indomethacin and granules prepared by the compression technique. This can be mainly attributed to the fact that this poorly water-soluble drug is already in solution absorbed on powder particles of the carrier of the liquisolid formulation (47). 
B. Vraníková and J. Gajdziok: Liquisolid systems and aspects influencing their research and development, Acta Pharm. 63 (2013) $447-465$.

Table II. List of several investigated liquisolid systems for enhanced drug release

\begin{tabular}{|c|c|c|c|}
\hline Drug & Liquid vehicle & Carrier & Coating matrial \\
\hline Bromhexine $\mathrm{HCl}$ (39) & $\begin{array}{l}\text { propylene glycol } \\
\text { PEG } 400\end{array}$ & $\mathrm{MCC}$ & Aerosil $^{\circledR} 200$ \\
\hline Carbamazepine (74) & PEG 400 & $\begin{array}{l}\text { Starch } 1500 \\
\text { MCC }\end{array}$ & OMS \\
\hline Ezetimibe (81) & $\begin{array}{l}\text { PEG } 400 \\
\text { polysorbate } 80 \\
\text { Labrasol }^{\circledR} \\
\text { Transcutol }^{\circledR} \text { HP }\end{array}$ & $\mathrm{MCC}$ & Aerosil $^{\circledR} 200$ \\
\hline Felodipin (79) & $\begin{array}{l}\text { PEG } 400 \\
\text { polysorbate } 80 \\
\text { propylene glycol }\end{array}$ & MCC & $\begin{array}{l}\text { Aerosil }^{\circledR} 200 \\
\text { Aeroperl }^{\circledR}\end{array}$ \\
\hline Flutamide (25) & PEG 400 & MCC & Aerosil $^{\circledR} 200$ \\
\hline Glyburide (27) & $\begin{array}{l}\text { propylene glycol } \\
\text { polysorbate } 80 \\
\text { glycerin } \\
\text { PEG } 400\end{array}$ & $\mathrm{MCC}$ & Aerosil $^{\circledR} 200$ \\
\hline Griseofulvin (49) & $\begin{array}{l}\text { PEG } 300 \\
\text { Cremophor }^{\circledR} \text { EL }\end{array}$ & $\begin{array}{l}\text { MCC } \\
\text { Neusilin }{ }^{\circledR} \\
\text { lactose }\end{array}$ & $\begin{array}{l}\text { Aerosil }^{\circledR} 200 \\
\text { Neusilin }{ }^{\circledR} \\
\text { Cab-O-Sil }^{\circledR} \text { M-5 }\end{array}$ \\
\hline Loratadine (24) & propylene glycol & MCC & Aerosil $^{\circledR} 200$ \\
\hline Nifedipin (93) & polysorbate 20 & $\begin{array}{l}\text { MCC } \\
\text { Fujicalin }{ }^{\circledR} \\
\text { Neusilin }^{\circledR}\end{array}$ & Aerosil $^{\circledR} 200$ \\
\hline Repaglinide (29) & polysorbate 80 & $\mathrm{MCC}$ & calciumsilicate \\
\hline Spironolactone (52) & $\begin{array}{l}\text { Synperonic }{ }^{\circledR} \mathrm{PE} / \mathrm{L} 61 \\
+ \text { Solutol }^{\circledR} \mathrm{HS}-15 \\
\text { Kollicoat }^{\circledR} \text { SR } 30 \text { D }\end{array}$ & $\mathrm{MCC}$ & Cab-O-Sil ${ }^{\circledR}$ M-5 \\
\hline Valsartan (94) & propylene glycol & MCC & Aerosil $^{\circledR} 200$ \\
\hline
\end{tabular}

LIQUISOLID SYSTEMS FOR MODIFIED DRUG RELEASE

Development of modified release oral dosage forms is beneficial for optimal therapy in terms of efficacy, safety and patient compliance. It is suggested that liquisolid systems have the potential to be optimized for decrease of the drug dissolution rate and thereby production of prolonged release preparations (matrix tablets, film-coated dosage forms, microparticles, etc.) $(20,92)$. 
The advantages of liquisolid systems to be used in prolonged release systems include simplicity, low cost and suitability for industrial production (92). However, only a few drugs (propranolol $\mathrm{HCl}$ (35), theophylline (36), griseofulvin (53) and tramadol $\mathrm{HCl}$ (33) have been formulated as liquisolid systems with prolonged drug release.

Liquisolid formulations with prolonged drug release may contain hydrophobic carriers such as Eudragit ${ }^{\circledR} \mathrm{RL}$ or RS instead of hydrophilic carriers. Hydrophobic carriers could lead to poor wetting properties of liquisolid systems, resulting in inadequate access of hydrophilic dissolution media into the structure of the liquisolid compact and thus prolonged drug release (95). Javadzadeh et al. (35) have proved that a liquid vehicle may affect drug release. They provide evidence that polysorbate 80 plays an important role in sustaining the release of propranolol hydrochloride from liquisolid matrix systems containing Eudragit ${ }^{\circledR} \mathrm{RL}$ or RS as carrier material. It was shown that the liquid vehicle polysorbate may act as a plasticizer and thus decrease the glass transition temperature $\left(T_{\mathrm{g}}\right)$ of the used polymer (Eudragit ${ }^{\circledR} \mathrm{RS}$ ). Plasticizers affect the intermolecular bonding between polymer chains, thereby increasing their flexibility. At temperature above $T_{\mathrm{g}}$, a better coalescence of polymer particles occurs, and a fine network and matrix with low porosity forms. This results in decreased entrance of dissolution media into the compact structure. Therefore, reduction of $T_{\mathrm{g}}$ of the polymer might be the reason for release prolongation of liquisolid tablets (35).

Another way to sustain the release from liquisolid systems is combination of hydrophilic carriers with the release modifying agent (e.g. hydroxypropyl methylcellulose) $(53,92)$. Gonjari et al. (33) proved that addition of HPMC to hydrophilic carrier (Avicel $\mathrm{PH}$ 102) prolonged tramadol hydrochloride release from liquisolid tablets. It was found that liquisolid compacts show a higher prolongation effect compared to conventional formulations.

\section{CONCLUSIONS}

Liquisolid systems essentially refer to formulations formed by conversion of the drug in liquid state into dry, non-adherent, free flowing and compressible powder by sorbing the liquid dispersion system to the carrier and coating material. Liquisolid systems show significantly improved bioavailability of drugs due to increased solubility and dissolution rate of poorly water-soluble substances. The liquisolid technique can be also used to design dosage forms with modified release by using hydrophobic carriers instead of hydrophilic carriers. However, the technology of liquisolid systems is in the early stages of its development. It is envisaged that liquisolid systems could play an important role in modern solid dosage forms owing to their advantages (e.g., low production costs, final processing similar to conventional tablets or hard capsules, and unproblematic industrial production).

Acknowledgement. - This article was completed with the support of IGA VFU Brno, Czech Republic, research project No. 82/2013/FaF. 


\section{REFERENCES}

1. M. Yazdanian, K. Briggs, C. Jankovsky and A. Hawi, The "high solubility« definition of the current FDA Guidance on Biopharmaceutical Classification System may be too strict for acidic drugs, Pharm. Res. 21 (2004) 293-299; DOI: 10.1023/B:PHAM.0000016242.48642.71.

2. L. X. Yu, G. L. Amidon, J. E. Polli, H. Zhao, M. U. Mehta, D. P. Conner, V. P. Shah, L. J. Lesko, M. Chen, V. H. L. Lee and A. S. Hussain, Biopharmaceutics classification system: The scientific basis for biowaiver extensions, Pharm. Res. 19 (2002) 921-925; DOI: 10.1023/A:1016473601633.

3. A. V. Yadav, A. S. Shete and A. P. Dabke, Formulation and evaluation of orodispersible liquisolid compacts of aceclofenac, Ind. J. Pharm. Educ. 44 (2010) 227-235.

4. Y. Javadzadeh, M. R. Siahi, S. Asnaashari and A. Nokhodchi, Liquisolid technique as a tool for enhancement of poorly water-soluble drugs and evaluation of their physicochemical properties, Acta Pharm. 57 (2007) 99-109; DOI: 10.2478/v10007-007-0008-6.

5. S. Nazzal and M. A. Khan, Controlled release of a self-emulsifying formulation from a tablet dosage form: Stability assessment and optimization of some processing parameters, Int. J. Pharm. 315 (2006) 110-121; DOI: 10.1016/j.ijpharm.2006.02.019.

6. N. Rasenack and B. W. Müller, Dissolution rate enhancement by in situ micronization of poorly water-soluble drugs, Pharm. Res. 19 (2002) 1894-1900; DOI: 10.1023/A:1021410028371.

7. A. B. Nighute and S. B. Bhise, Enhancement of dissolution rate of Rifabutin by preparation of microcrystals using solvent change method, Int. J. Pharm. Tech. Res. 1 (2009) 142-148.

8. G. V. Betager and K. R. Makarla, Enhancement of dissolution of glyburide by solid dispersion and lyophilization techniques, Int. J. Pharm. 126 (1995) 155-160; DOI: 10.1016/0378-5173(95) 04114-1.

9. J. W. Millard, F. A. Alvarez-Núñez and S. H. Yalkowsky Solubilization by cosolvents establishing useful constants for the log-linear model, Int. J. Pharm. 245 (2002) 153-166; DOI: 10.1016/ S0378-5173(02)00334-4.

10. P. Balakrishnan, B. Le, D. H. Oh, J. O. Kim, M. J. Hong, J. Jee, J. A. Kim, B. K. Yoo, J. S. Woo, C. S. Yong and H. Choi, Enhanced oral bioavailability of dexibuprofen by a novel solid self-emulsifying drug delivery system (SEDDS), Eur. J. Pharm. Biopharm. 72 (2009) 539-545; DOI: 10.1016/j. ejpb.2009.03.001.

11. A. Zvonar, K. Berginc, A. Kristl and M. Gašperlin, Microencapsulation of self-microemulsifying system: Improving solubility and permeability of furosemide, Int. J. Pharm. 388 (2010) 151-158; DOI: 10.1016/j.ijpharm.2009.12.055.

12. H. A. Hassan, A. H. Al-Marzouqi, B. Jobe, A. A. Hamza and G. A. Ramadan, Enhancement of dissolution amount and in vivo bioavailability of itraconazole by complexation with $\beta$-cyclodextrin using supercritical carbon dioxide, J. Pharmaceut. Biomed. 45 (2007) 243-250; DOI: 10.1016/j. jpba.2007.06.011.

13. T. Tanino, T. Ogiso, M. Iwaki, G. Tanabe and O. Muraoka, Enhancement of oral bioavailability of phenytoin by esterification, and in vitro hydrolytic characteristics of prodrugs, Int. J. Pharm. 163 (1998) 91-102; DOI: 10.1016/S0378-5173(97)00374-8.

14. S. G. Kapsi and J. W. Ayres, Processing factors in development of solid solution formulation of itraconazole for enhancement of drug dissolution and bioavailability, Int. J. Pharm. 229(2001) 193-203; DOI: 10.1016/S0378-5173(01)00867-5.

15. D. X. Li, Y. Oh, S. Lim, J. O. Kim, H. J. Yang, J. H. Sung, C. S. Yong and H. Choi, Novel gelatin microcapsule with bioavailability enhancement of ibuprofen using spray-drying technique, Int. J. Pharm. 355 (2008) 277-284; DOI: 10.1016/j.ijpharm.2007.12.020.

16. V. Stella, J. Haslam, N. Yata, H. Okada, S. Lindenbaum and T. Higuchi, Enhancement of bioavailability of a hydrophobic amine antimalarial by formulation with oleic acid in a soft gelatin capsule, J. Pharm. Sci. 67 (1978) 1375-1377. 
17. V. K. Nagabandi, T. Ramarao and K. N. Jayaveera, Liquisolid compacts: A novel approach to enhance bioavailability of poorly soluble drugs, Int. J. Pharm. Biol. Sci. 1 (2011) 89-102.

18. N. Tiong and A. A. Elkordy, Effects of liquisolid formulations on dissolution of naproxen, Eur. J. Pharm. Biopharm. 73 (2009) 373-384; DOI: 10.1016/j.ejpb.2009.08.002.

19. K. Kavitha, K. N. S. LovaRaju, N. S. Ganesh and B. Ramesh, Effect of dissolution rate by liquisolid compacts approach: An overview, Der Pharmacia Lettre 3 (2011) 71-83.

20. A. S. Kulkarni, N. H. Aloorkar, M. S. Mane and J. B. Gaja, Liquisolid systems: a review, Int. J. Pharm. Sci. Nanotechnol. 3 (2010) 795-802.

21. S. M. Gavali, S. S. Pacharane, S. V. Sankpal, K. R. Jadhav and V. J. Kadam, Liquisolid compact: A new technique for enhancement of drug dissolution, Int. J. Res. Pharm. Chem. 1 (2011) 705-713.

22. A. B. Karmarkar, I. D. Gonjari, A. H. Hosmani, P. N. Dhabale and S. B. Bhise, Liquisolid tablets: A novel approach for drug delivery, Int. J. Health Res. 2 (2009) 45-50.

23. A. B. Karmarkar, I. D. Gonjari and A. H. Hosmani, Liquisolid technology for dissolution rate enhancement or sustained release, Expert Opin. Drug Deliv. 7 (2010) 1227-1234; DOI: 10.1517/ 17425247.2010.511173.

24. M. El-Hammadi and N. Awad, Investigating the use of liquisolid compacts technique to minimize the influence of $\mathrm{pH}$ variations on loratadine release, AAPSPharmSciTech. 13 (2012) 53-58; DOI: $10.1208 /$ s12249-011-9719-6.

25. A. K. Elkhodairy and M. W. Samy, Optimization and evaluation of micromeritic and release properties of high dose flutamide liquisolid systems, Lett. Drug Des. Discov. 9 (2012) 336-344; DOI: $10.2174 / 157018012799129873$.

26. Y. Javadzadeh, B. Jafari-Navimipour and A. Nokhodchi, Liquisolid technique for dissolution rate enhancement of a high dose water-insoluble drug (carbamazepine), Int. J. Pharm. 341 (2007) 26-34; DOI: 10.1016/j.ijpharm.2007.03.034.

27. S. K. Singh, K. K. Srinivasan, K. Gowthamarajan, D. Prakash, N. B. Gaikwad and D. S. Singare, Influence of formulation parameters on dissolution rate enhancement of glyburide using liquisolid technique, Drug Dev. Ind. Pharm. 38 (2012) 961-970; DOI: 10.3109/03639045.2011.634810.

28. C. M. Hentzschel, A. Sakmann and C. S. Leopold, Suitability of various excipients as carrier and coating materials for liquisolid compacts, Drug Dev. Ind. Pharm. 37 (2011) 1200-1207; DOI: 10.3109/03639045.2011.564184.

29. B. M. El-Houssieny, L. F. Wahman and N. M. Arafa, Bioavailability and biological activity of liquisolid compact formula of repaglinide and its effect on glucose tolerance in rabbits, Biosci. Trends. 4 (2010) 17-24.

30. K. A. Khaled, Y. A. Asiri and Y. M. El-Sayed, In vivo evaluation of hydrochlorothiazide liquisolid tablets in beagle dogs, Int. J. Pharm. 222 (2001) 1-6; DOI: 10.1016/S0378-5173(01)00633-0.

31. B. Chen, Z. Wang, G. Quan, X. Peng, X. Pan, R. Wang, Y. XU, G. Li and C. Wu, In vitro and in vivo evaluation of ordered mesoporous silica as a novel adsorbent in liquisolid formulation, Int. J. Nanomed. 7 (2012) 199-209; DOI: 10.2147/IJN.S26763.

32. R. H. Fahmy and M. A. Kassem, Enhancement of famotidine dissolution rate through liquisolid tablets formulation: In vitro and in vivo evaluation, Eur. J. Pharm. Biopharm. 69(2008) 993-1003; DOI: 10.1016/j.ejpb.2008.02.017.

33. I. D. Gonjari, A. B. Karmarkar and A. H. Hosmani, Evaluation of in vitro dissolution profile comparison methods of sustained release tramadol hydrochloride liquisolid compact formulations with marketed sustained release tablets, Dig. J. Nanomater. Bios. 4 (2009) 651-661.

34. H. S. Mahajan, M. R. Dhamne, S. G. Gattani, A. D. Rasal and H. T. Shaikh, Enhanced dissolution rate of glipizide by a liquisolid technique, Int. J. Pharm. Sci. Nanotech. 3 (2011) 1205-1213.

35. Y. Javadzadeh, L. Musaalrezaei and A. Nokhodchi, Liquisolid technique as a new approach to sustain propranolol hydrochloride release from tablet matrices, Int. J. Pharm. 362 (2008) 102108; DOI: 10.1016/j.ijpharm.2008.06.022. 
36. A. Nokhodchi, R. Aliakbar, S. Desai and Y. Javadzadeh, Liquisolid compacts: The effect of cosolvent and HPMC in theophylline release, Colloid Surface B. 79 (2010) 262-269; DOI: 10.1016/j. colsurfb.2010.04.008.

37. Center for the Evaluation of Risks to Human Reproduction, NTP-CERHR Expert Panel report on the reproductive and developmental toxicity of propylene glycol, Reprod. Toxicol. 18 (2004) 533-579; DOI: 10.1016/j.reprotox.2004.01.004.

38. Cefic, Propylene Glycol - Pharmaceuticals, n.d.; http://www.propylene-glycol.com/index. php/propylene-glycol-ups-ep-pharmaceutical-grade/pharmaceuticals, access date January 17, 2012.

39. S. Gubbi and R. Jarag, Liquisolid Technique for enhancement of dissolution properties of bromhexine hydrochloride, Res. J. Pharm. Tech. 2 (2009) 382-386.

40. BASF group, Lutrol ${ }^{\circledR}$ E Liquid Grades, 2010; http://www.pharma-ingredients.basf.com/Statements/Technical\%20Informations/EN/Pharma\%20Solutions/03_030734e_Lutrol\%20E\%20-\% 20Liquid\%20Grades.pdf; access date January 18, 2012.

41. R. C. Rowe, P. J. Sheskey and S. C. Owen, Handbook of Pharmaceutical Excipients, $5^{\text {th }}$ ed., Pharmaceutical Press, London 2006, p. 918.

42. C. F. Daher, G. M. Baroody and R. J. Howland, Effect of a surfactant, Tween 80, on the formation and secretion of chylomicrons in the rat, Food Chem. Toxicol. 41 (2003) 575-582; DOI: 10.1016/ S0278-6915(02)00299-5.

43. T. Tatsuishi, Y. Oyama, K. Iwase, J. Y. Yamaguchi, M. Kobayashi, Y. Nishimura, A. Kanada and S. Hirama, Polysorbate 80 increases the susceptibility to oxidative stress in rat thymocytes, Toxicology 207 (2005) 7-14; DOI: 10.1016/j.tox.2004.07.020.

44. W. Wang, Y. J. Wang and D. Q. Wang, Dual effect of Tween 80 on protein stability, Int. J. Pharm. 347 (2008) 31-38; DOI: 10.1016/j.ijpharm.2007.06.042.

45. S. A. Tayel, I. I. Soliman and D. Louis, Improvement of dissolution properties of carbamazepine through application of the liquisolid tablet technique, Eur. J. Pharm. Biopharm. 69 (2008) 342-347; DOI: 10.1016/j.ejpb.2007.09.003.

46. M. Saeedi, J. Akbari, K. Morteza-Semnani, R. Enayati-Fard, S.Sar-Reshteh-dar and A. Soleymani, Enhancement of dissolution rate of indomethacin using liquisolid compacts, Iran J. Pharm. Res. 10 (2011) 25-34.

47. V. B. Yadav and A. V. Yadav, Improvement of solubility and dissolution of indomethacin by liquisolid and compaction granulation technique, J. Pharm. Sci. Res. 1 (2009) 44-51.

48. Y. Javadzadeh, M. R. Siahi-Shadbad, M. Barzegar-Jalali and A. Nokhodchi, Enhancement of dissolution rate of piroxicam using liquisolid compacts, Il Farmaco 60 (2005) 361-365; DOI: 10. 1016/j.farmac.2004.09.005.

49. A. A. Elkordy, U. Bhangale, N. Murle and M. F. Zarara, Combination of lactose (as a carrier) with Cremophor ${ }^{\circledR}$ EL (as a liquid vehicle) to enhance dissolution of griseofulvin, Powder Technol. 246 (2013) 182-186; DOI: 10.1016/j.powtec.2013.05.024.

50. B. Akinlade, A. A. Elkordy, E. A. Essa and S. Elhagar, Liquisolid systems to improve the dissolution of furosemide, Sci. Pharm. 78 (2010) 325-344; DOI: 10.3797/scipharm.0912-23.

51. C. C. Liao and C. I. Jarowski, Dissolution rates of corticoid solutions dispersed on silicas, J. Pharm. Sci. 73 (1984) 401-403; DOI: 10.1002/jps.2600730330.

52. A. A. Elkordy, X. N. Tan and E. A. Essa, Spironolactone release from liquisolid formulations prepared with Capryol ${ }^{\mathrm{TM}}$ 90, Solutol ${ }^{\circledR}$ HS-15 and Kollicoat ${ }^{\circledR}$ SR 30 D as non-volatile liquid vehicles, Eur. J. Pharm. Biopharm. 83 (2013) 203-223; DOI: 10.1016/j.ejpb.2012.08.004.

53. A. A. Elkordy, E. A. Essa, S. Dhuppad and P. Jammiqumpula, Liquisolid technique to enhance and to sustain griseofulvin dissolution: effect of choice of non-volatile liquid vehicles, Int. J. Pharm. 434 (2012) 122-132; DOI: 10.1016/j.ijpharm.2012.05.072. 
54. V. Agarwal, A. Siddiqui, H. Ali and S. Nazzal, Dissolution and power flow characterization of solid self-emulsified drug delivery system (SEDDS), Int. J. Pharm. 366 (2009) 44-52; DOI: 10. 1016/j.ijpharm.2008.08.046.

55. G. Kahr and F. T. Madsen, Determination of the cation exchange capacity and the surface area of bentonite, illite and kaolinite by methylene blue absorption, Appl. Clay Sci. 9 (1995) 327-336; DOI: 10.1016/0169-1317(94)00028-O.

56. M. Van Speybroeck, R. Mellaerts, R. Mols, T. D. Thi, J. A. Martens, J. Van Humbeeck, P. Annaert, G. Van den Mooter and P. Augistijns, Enhanced absorption of the poorly soluble drug fenofibrate by tuning its release rate from ordered mesoporous silica, Eur. J. Pharm. Sci. 41 (2010) 623-630; DOI: 10.1016/j.ejps.2010.09.002.

57. V. B. Yadav, A. B. Nighute, A. V. Yadav and S. B. Bhise, Aceclofenac size enlargement by non-aqueous granulation with improved solubility and dissolution, Arch. Pharm. Sci. Res. 1 (2009) 115-122.

58. P. G. Manogar, B. N. V. Hari and D. R. Devi, Emerging liquisolid compact technology for solubility enhancement of BCS Class-II drug, J. Pharm. Sci. Res. 3 (2011) 1604-1611.

59. Fuji Chemical Industry Co., Ltd., Neusilin - Generel Properties, 2010; http://www.neusilin. com/product/general_properties.php; access date October 18, 2012.

60. C. M. Hentzschel, M. Alnaief, I. Smirnova, A. Sakmann and C. S. Leopold, Tableting properties of silica aerogels and other silicates, Drug Dev. Ind. Pharm. 38 (2012) 462-467; DOI: 10.3109/ 03639045.2011.611806.

61. Fuji Chemical Industry Co., Ltd., Neusilin, 2011; http:/ /www.fujichemical.co.jp/english/medical/medicine/neusilin/index.html; access date October 18, 2012.

62. Fuji Chemical Industry Co., Ltd., The Specialty Excipient Neusilin ${ }^{\circledR}$, 2009; http://www.harke. com/fileadmin/images/pharma/Broschueren/Fuji_Neusilin.pdf; access date January 18, 2012.

63. X. Zhao, Y. Q. Zhou, S. Potharaju, H. Lou, H. M. Sun, E. Brunson, H. Almoazen and J. Johnson, Development of a self micro-emulsifying tablet of cyclosporine-A by the liquisolid compact technique, Int. J. Pharm. Sci. Res. 2 (2011) 2299-2308.

64. B. Van Eerdenbrugh, L. Froyen, J. Van Humbeeck, J. A. Martens, P. Augustijns and G. Van Den Mooter, Alternative matrix formers for nanosupension solidification: Dissolution performance and X-ray microanalysis as an evaluation tool for powder dispersion, Eur. J. Pharm. Sci. 35 (2008) 344-353; DOI: 10.1016/j.ejps.2008.08.003.

65. M. J. Kang, S. Y. Jung, W. H. Song, J. S. Park, S. U. Choi, K. T. Oh, H. K. Choi, Y. W. Choi, J. Lee, B. J. Lee and S. C. Chi, Immediate release of ibuprofen from Fujicalin ${ }^{\circledR}$-based fast-dissolving self-emulsifying tablets, Drug Dev. Ind. Pharm. 37 (2011) 1298-1305; DOI: 10.3109/03639045. 2011.571695.

66. H. Schlack, A. Bauer-Brandl, R. Schubert and D. Becker, Properties of Fujicalin ${ }^{\circledR}$, A new modified anhydrous dibasic calcium phosphate for direct compression: Comparison with dicalcium phosphate dihydrate, Drug Dev. Ind. Pharm. 27 (2001) 789-801.

67. Z. Wu, Y. Jiang, T. Kim and K. Lee, Effect of surface coating on the controlled release of vitamin B1 from mesoporous silica tablets, J. Control. Release 119 (2007) 215-221; DOI: 10.1016/j.jconrel. 2007.03.001.

68. T. Ukmar and O. Planinšek, Ordered mesoporous silicates as matrices for controlled release of drugs, Acta Pharm. 60 (2010) 373-385; DOI: 10.2478/v1007-010-0037-4.

69. M. Vallet-Regi, A. Ramila, R. P. del Rea and J. Pérez-Pariente, A new property of MCM-41: drug delivery system, Chem. Mater. 13 (2001) 308-311; DOI: 10.1021/cm0011559.

70. R. Mellaerts, R. Mois, J. A. G. Jammaer, C. A. Aerts, P. Annaert, J. Van Humbeeck, G. Van den Mooter, P. Augustijns and J. A. Martens, Increasing the oral bioavailability of the poorly water soluble drug itraconazole with ordered mesoporous silica, Eur. J. Pharm. Biopharm. 69 (2008) 223-230; DOI: 10.1016/j.ejpb.2007.11.006. 
71. M. Vialpando, F. Backhuijs, J. A. Martens and G. Van den Mooter, Risk assessment of premature drug release during wet granulation of ordered mesoporous silica loaded with poorly soluble compounds intraconazole, fenofibrate, naproxen, and ibuprofen, Eur. J. Pharm. Biopharm. 81 (2012) 190-198; DOI: 10.1016/j.ejpb.2012.01.012.

72. T. Heikkilä, J. Salonen, J. Tuura, N. Kumar, T. Salmi, D. Y. Murzin, M. S. Hamdy, G. Mul, L. Laitinen, A. M. Kaukonen, J. Hirvonen and V. P. Lehto, Evaluation of mesoporous TCPSi, MCM-41, SBA-15 and TUD-1 materials as API carriers for oral drug delivery, Drug Deliv. 14 (2007) 337-347; DOI: 10.1080/10717540601098823.

73. M. Van Speybroeck, V. Barillaro, T. D. Thi, R. Mellaerts, J. Martens, J. Van Humbeeck, J. Vermant, P. Annaert, G. Van den Mooter and P. Augustijns, Ordered mesoporous silica material SBA-15: a broad-spectrum formulation platform for poorly soluble drugs, J. Pharm. Sci. 98 (2009) 2648-2658; DOI: 10.1002/jps.21638.

74. B. Chen, G. Quan, Z. Wang, J. Chen, L. Wu, Y. Xu, G. Li and C. Wu, Hollow mesoporoussilicas as a drug solution delivery system for insoluble drugs, Powder Technol. 240 (2013) 48-53; DOI: 10.1016/j.powtec.2012.07.008.

75. S. R. Gubbi and R. Jarag, Formulation and characterization of atorvastatin calcium liquisolid compacts, Asian J. Pharm. Sci. 5 (2010) 50-60.

76. K. M. El-Say, A. M. Samy and M. I. Fetouh, Formulation and evaluation of rofecoxib liquisolid tablets, Int. J. Pharm. Sci. Rev. Res. 3 (2010) 135-142.

77. A. Krupa, D. Majda, R. Jachowicz and W. Mozgawa, Solid-state interaction of ibuprofen and Neusilin US2, Thermochim. Acta 509 (2010) 12-17; DOI: 10.1016/j.tca.2010.05.009.

78. A. Sheth and C. I. Jarowski, Use of powdered solutions to improve the dissolution rate of polythiazide tablets, Drug Dev. Ind. Pharm. 16 (1990) 769-777; DOI: 10.3109/03639049009114908.

79. E. B. Basalious, W. El-Sebaie and O. El-Gazayerly, Rapidly absorbed orodispersible tablet containing molecularly dispersed felodipine for management of hypertensive crisis: Development, optimization and in vitro/in vivo studies, Pharm. Dev. Technol. 18 (2013) 407-416; DOI: 10.3109/ 10837450.2012.659258.

80. S. S. Spireas, C. I. Jarowski and B. D. Rohera, Powdered solution technology: Principles and mechanism, Pharm. Res. 9 (1992) 1351-1358; DOI: 10.1023/A:1015877905988.

81. M. Khanfar, S. M. Sheikh and R. Hawari, Formulation factors affecting the release of ezetimibe from different liquisolid compacts, Pharm. Dev. Technol. 18 (2013) 417-427; DOI: 10.3109/ 10837450.2012.680594.

82. S. Spireas and S. M. Bolton, Liquisolid Systems and Methods of Preparing Same, US 5,968,550, 19 October 1999.

83. S. Spireas and S. M. Bolton SM, Liquisolid Systems and Methods of Preparing Same, US 6,423,339, 23 July 2002.

84. K. Rajesh, R. Rajalakshmi, J. Umamaheswari and C. K. A. Kumar, Liquisolid technique: a novel approach to enhance solubility and bioavailability, Int. J. Biopharm. 2 (2011) 8-13.

85. R.Grover, S. Spireas and C. Lau-Cam, Development of a simple spectrophotometric method for propylene glycol detection in tablets, J. Pharm. Biomed. Anal. 16 (1998) 931-938; DOI: 10.1016/ S0731-7085(97)00098-8.

86. R. Boghra, A. Patel, H. Desai and A. Jadhav, Formulation and evaluation of irbesartan liquisolid tablets, Int. J. Pharm. Sci. Rev. Res. 9 (2011) 32-37.

87. S. V. Kasture, S. B. Gondkar, A. B. Darekar, D. Priyobrata and K. V. Bhambar, Enhancement of dissolution rate of lansoprazole using liquisolid tablet technique, Int. J. Pharm. Res. 3 (2011) 2731.

88. M. A. Hassan and H. M. El-Saghir, Enhancement of dissolution and the anti-inflammatory effect of nimesulide, using liquisolid compact for oral appliccation, Bull. Pharm. Sci. 34 (2011) 1-8. 
B. Vraníková and J. Gajdziok: Liquisolid systems and aspects influencing their research and development, Acta Pharm. 63 (2013) $447-465$.

89. The European Directorate for the Quality of Medicines \& Health Care, European Pharmacopoeia 7.2, 2011; http:/ / online6.edqm.eu/ep702/; access date February 18, 2012.

90. D. C. Bibby, N. M. Davies and I. G. Tucker, Mechanisms by which cyclodextrins modify drug release from polymeric drug delivery systems, Int. J. Pharm. 197 (2000) 1-11; DOI: 10.1016/S03785173(00)00335-5.

91. D. Q. Craig, The mechanisms of drug release from solid dispersions in water-soluble polymers, Int. J. Pharm. 231 (2002) 131-144; DOI: 10.1016/S0378-5173(01)00891-2.

92. A. Nokhodchi, C. M. Hentzschel and C. S. Leopold, Drug release from liquisolid systems: speed it up, slow it down, Expert Opin. Drug Deliv. 8 (2011) 191-205; DOI: 10.1517/17425247.2011. 548801.

93. A. Panda and D. M. Biyani, Studies on liquisolid system as a technique to modify the dissolution rate of nefedipine, Am. J. Pharmtech. Res. 3 (2013) 686-698.

94. N. Chella, N. Shastri and R. R. Tadikonda, Use of the liquisolid compact technique for improvement of the dissolution rate of valsartan, Acta Pharm. Sin B. 2 (2012) 502-508; DOI: 10.1016/j. apsb.2012.07.005..

95. N. Thakur, S. L. Khokra, D. Sharma, N. S. Thakur, R. Purohit and V. Arya, A review on pharmaceutical application of liquisolid technique, Am. J. Pharmtech. Res. 1 (2011) 1-18. 